\title{
Depression in Vascular Dementia Is Quantitatively and Qualitatively Different from Depression in Alzheimer's Disease
}

\author{
J.H. Park ${ }^{a}$ S.B. Lee ${ }^{a}$ T.J. Lee ${ }^{a}$ D.Y. Lee ${ }^{d, e} \quad$ J.H. Jhoo ${ }^{f}$ J.C. Youn ${ }^{\text {C }}$ I.H. Choo ${ }^{d}$ \\ E.A.Choi ${ }^{a}$ J.W. Jeong ${ }^{a}$ J.Y. Choe ${ }^{a}$ J.I. Woo ${ }^{\text {d, e }}$ K.W. Kim ${ }^{\text {a, b, e }}$ \\ a Department of Neuropsychiatry and ${ }^{b}$ Stroke Center, Seoul National University Bundang Hospital, and \\ 'Department of Neuropsychiatry, Kyunggi Provincial Hospital for the Elderly, Gyeonggido, dDepartment of \\ Neuropsychiatry, Seoul National University Hospital, and 'Seoul National University College of Medicine, Seoul, \\ and ${ }^{\mathrm{f}}$ Department of Neuropsychiatry, Kangwon University College of Medicine, Kangwondo, Korea
}

\section{Key Words}

Major depressive disorder • Minor depressive disorder •

Vascular dementia - Alzheimer's disease

\begin{abstract}
Background/Aims: To compare the prevalence and characteristics of depression in vascular dementia (VaD) and Alzheimer's disease (AD) after adjusting for dementia severity and gender. Methods: One hundred and eight pairs of VaD and AD patients matched for dementia severity and gender were assessed. Results: Major depressive disorder (MDD) was more prevalent in the $\mathrm{VaD}$ group than in the $\mathrm{AD}$ group (20.4\% in $\mathrm{VaD}, 10.2 \%$ in $\mathrm{AD}, \mathrm{p}=0.04$, Cochran-MantelHaenszel, $\mathrm{CMH}$, test) regardless of the dementia severity and gender. The odds ratio for developing MDD in the VaD group versus the $A D$ group was estimated to be 2.20 (95\% confidence interval $=1.02-4.74)$. Neurovegetative symptoms such as 'felt tired and weak all the time' (30.6\% in VaD, 13.9\% in $A D, p=0.003, C M H$ test) and 'changed weight without trying' (16.7\% in VaD, 6.5\% in $A D, p=0.02, C M H$ test) were more prevalent in the VaD group than in the AD group. Conclusion: Depression in $\mathrm{VaD}$ was quantitatively and qualitatively different from that in AD regardless of the severity of demen-
\end{abstract}

tia and gender; depression was more prevalent, severer and more retarded and vegetative in $\mathrm{VaD}$ than in $\mathrm{AD}$.

Copyright $\odot 2007$ S. Karger AG, Basel

\section{Introduction}

Depression commonly accompanies vascular dementia (VaD) and Alzheimer's disease (AD). Depression in dementia is clinically important because it is a significant but treatable determinant of morbidity and caregiver distress $[1,2]$. According to the populations surveyed, the assessment methodologies employed and the diagnostic criteria applied, the prevalence rate of major depressive disorder (MDD) varies widely and has been reported to be $19-45 \%$ in $\mathrm{VaD}$ patients $[3,4]$ and $8-20 \%$ in $\mathrm{AD}$ patients [3-6].

In $\mathrm{AD}$, depression may be caused by neurodegenerative changes in brain regions that are involved in mood regulation. $\mathrm{AD}$ patients with depression were found to show neurodegenerative changes in brainstem aminergic nuclei with relative preservation of basal forebrain cholinergic neurons that innervate the hippocampi and neocortices [7-10]. On the other hand, the involvement of

\section{KARGER}

Fax +4161306 1234 E-Mail karger@karger.ch www.karger.com
(C) 2007 S. Karger AG, Basel

$1420-8008 / 07 / 0232-0067 \$ 23.50 / 0$

Accessible online at:

www.karger.com/dem
Ki Woong Kim, MD, PhD

Department of Neuropsychiatry, Seoul National University College of Medicine and Seoul National University Bundang Hospital

300 Gumidong, Bundanggu, Seongnamsi, Gyeonggido 463-707 (Korea)

Tel. +82 31787 7432, Fax +82 31787 4058, E-Mail kwkimmd@snu.ac.kr 
white matter and subcortical gray matter may account for the genesis of depression in VaD. Subcortical pathologies in the forms of leukoaraiosis, Binswanger's disease or lacunar states are present in the majority of $\mathrm{VaD}$ patients and may be the sole finding in $40 \%$ of $\mathrm{VaD}$ patients [11, 12]. Although no consensus has been reached on the relationship between depression and cerebral lesion location [13], damage to striatopallidothalamocortical pathways may play an important role in the development of depression via altering the serotonergic and adrenergic circuits [14].

However, it has been debated whether depression in $\mathrm{VaD}$ is clinically distinct from that in $\mathrm{AD}$. Although depression has been reported to be more prevalent, severer and more vegetative in $\mathrm{VaD}$ than in $\mathrm{AD}$ in several studies $[4,15-18]$, it was not replicated in other studies [19-22]. Furthermore, dementia severity and gender were not considered in these studies. Since the prevalence and characteristics of depression are known to vary according to the severity of dementia, comparisons of depression in $\mathrm{VaD}$ and $\mathrm{AD}$ should be made on the basis of dementia severity. The genders of the $\mathrm{VaD}$ and $\mathrm{AD}$ subjects should also be considered since gender is a well-known risk factor for depression [23-25].

Therefore, we compared the prevalence and characteristics of depression in $\mathrm{VaD}$ and $\mathrm{AD}$ after matching subjects for dementia severity and gender to examine whether depressions in $\mathrm{VaD}$ and $\mathrm{AD}$ are quantitatively and qualitatively different.

\section{Materials and Methods}

Subjects were recruited from two dementia clinics (Seoul National University Hospital, Seoul National University Bundang Hospital) and memory screening programs offered to community residents in Seoul and Seongnam, Korea. The subjects were the first visitors for the evaluation of dementia and had not suffered from major psychiatric illnesses on axis I including MDD, bipolar disorder and schizophrenia before cognitive decline. The subjects had not taken or were not taking antidementia medications and antidepressants. All the subjects were Koreans.

All the subjects were administered a standardized clinical interview, physical and neurological examinations, and laboratory tests including either the brain CT or MRI according to the protocol of the Korean version of the CERAD assessment battery (CERAD-K) [26]. The modified Hachinski ischemic score [27] is included in CERAD-K.

Subsequently, all available information was reviewed by a panel of 4 experienced dementia research neuropsychiatrists for the determination of the Clinical Dementia Rating (CDR) index and diagnosis. Two of the research neuropsychiatrists were certified CDR raters at the Memory and Aging Project of Alzheimer's Dis-
Table 1. Demographic characteristics of $\mathrm{VaD}$ and $\mathrm{AD}$ patients

\begin{tabular}{lcc}
\hline & $\begin{array}{l}\text { VaD } \\
(\mathrm{n}=108)\end{array}$ & $\begin{array}{l}\mathrm{AD} \\
(\mathrm{n}=108)\end{array}$ \\
\hline Age, years & $71.45 \pm 7.37$ & $72.37 \pm 8.61$ \\
Sex, \% female & 50.90 & 50.90 \\
Education, years & $6.67 \pm 5.24$ & $6.86 \pm 5.29$ \\
Blessed dementia scale & $4.53 \pm 3.29$ & $3.00 \pm 2.87$ \\
Sum of boxes score of CDR & $6.34 \pm 4.18$ & $6.55 \pm 4.66$ \\
Modified Hachinski ischemic score & $7.61 \pm 2.95^{*}$ & $0.65 \pm 1.23$ \\
MMSE & $17.24 \pm 5.43^{*}$ & $14.88 \pm 6.50$ \\
\hline
\end{tabular}

${ }^{*} \mathrm{p}<0.01$, Student $\mathrm{t}$ test. MMSE $=$ Mini Mental State Examination.

ease Research Center, Washington University School of Medicine. Dementia was defined according to the DSM-IV diagnostic criteria [28]. VaD was diagnosed according to the National Institute of Neurological Disorders and Stroke/Association Internationale pour la Recherche et l'Enseignement en Neurosciences criteria [29], and AD was diagnosed according to the National Institute of Neurological and Communicative Disorders and Stroke and the Alzheimer's Disease and Related Disorders Association criteria [30]. Only probable $\mathrm{VaD}$ patients and probable $\mathrm{AD}$ patients were enrolled. The CDR indices and genders of $\mathrm{VaD}$ and AD patients were tightly matched.

Depressive symptoms were evaluated using the Depressive Symptom Checklist included in the CERAD-K. MDD was diagnosed according to the DSM-IV criteria and minor depressive disorder (MnDD) according to research criteria proposed in appendix B of the DSM-IV criteria. Subjects in whom MDD preceded cognitive decline were excluded.

Demographic characteristics and the measures that were continuous in nature were analyzed using analysis of variance, and the frequencies of depressive disorders and symptoms were compared using the Cochran-Mantel-Haenszel (CMH) test. No adjustments of the $\mathrm{p}$ value criterion were made for multiple comparisons, since the goal of the study was to explore differences between the two diagnostic groups and reduce the likelihood of the type II errors as well as type I error. The odds ratios (OR) for developing depressive disorders and symptoms in $\mathrm{VaD}$ versus $\mathrm{AD}$ were estimated using the Mantel-Haenszel test, and the homogeneity of OR was tested using the Breslow-Day (BD) test. All the statistical analyses were performed using SPSS version 11.0.

\section{Results}

One hundred and eight probable $\mathrm{VaD}$ patients and 108 gender- and CDR-matched AD patients were enrolled (table 1). The proportion of women was $50.9 \%$. Mean ages $(71.45 \pm 7.37$ years in $\mathrm{VaD}$ patients, $72.37 \pm 8.61$ years in $\mathrm{AD}$ patients) and levels of education (6.67 \pm 5.24 
Table 2. Frequencies of $\mathrm{MDD}$ and $\mathrm{MnDD}$ in the $\mathrm{VaD}$ and $\mathrm{AD}$ patients

\begin{tabular}{|c|c|c|c|c|}
\hline & \multicolumn{2}{|l|}{$\mathrm{MDD}^{1}$} & \multicolumn{2}{|l|}{$\mathrm{MnDD}$} \\
\hline & $\mathrm{VaD}(\mathrm{n}=108)$ & $\mathrm{AD}(\mathrm{n}=108)$ & $\mathrm{VaD}(\mathrm{n}=108)$ & $\mathrm{AD}(\mathrm{n}=108)$ \\
\hline \multicolumn{5}{|l|}{ Severity of dementia } \\
\hline Very mild $(\mathrm{CDR}=0.5, \mathrm{n}=78)$ & $8(20.5)$ & $4(10.3)$ & $7(17.9)$ & $6(15.4)$ \\
\hline Mild $(\mathrm{CDR}=1, \mathrm{n}=84)$ & $10(23.8)$ & $4(9.5)$ & $7(16.7)$ & $7(16.7)$ \\
\hline Moderate $(\mathrm{CDR}=2, \mathrm{n}=30)$ & $3(20.0)$ & $2(13.3)$ & $2(13.3)$ & $4(26.7)$ \\
\hline Severe $(\mathrm{CDR}=3, \mathrm{n}=24)$ & $1(8.3)$ & $1(8.3)$ & $1(8.3)$ & 0 \\
\hline \multicolumn{5}{|l|}{ Gender } \\
\hline Female $(\mathrm{n}=110)$ & $16(14.5)$ & $5(4.5)$ & $12(10.9)$ & $9(8.2)$ \\
\hline Male $(\mathrm{n}=106)$ & $6(5.7)$ & $6(5.7)$ & $5(4.7)$ & $8(7.5)$ \\
\hline Total $(\mathrm{n}=216)$ & $22(20.4)$ & $11(10.2)$ & $17(15.7)$ & $17(15.7)$ \\
\hline
\end{tabular}

years in $\mathrm{VaD}$ patients, $6.86 \pm 5.29$ years in $\mathrm{AD}$ patients) were similar in the two groups ( $\mathrm{p}>0.1$, Student $\mathrm{t}$ test).

The proportions of very mild $(\mathrm{CDR}=0.5)$, mild $(\mathrm{CDR}=1)$, moderate $(\mathrm{CDR}=2)$ and severe $(\mathrm{CDR} \geq 3)$ cases were $36.1 \%(n=39), 38.9 \%(n=42), 13.9 \%(n=15)$ and $11.1 \%(\mathrm{n}=12)$, respectively. Sum of boxes score of $\mathrm{CDR}(6.34 \pm 4.18$ in $\mathrm{VaD}$ patients, $6.55 \pm 4.66$ in $\mathrm{AD}$ patients, $\mathrm{p}>0.1$ by Student t test) and Blessed Dementia Scale scores $(4.53 \pm 3.29$ in $\mathrm{VaD}$ patients, $3.00 \pm 2.87 \mathrm{in}$ $\mathrm{AD}$ patients, $\mathrm{p}>0.1$ by Student $\mathrm{t}$ test) were similar in the two groups indicating that global severities and activities of daily living impairments were quite comparable.

However, the VaD group had a higher mean Mini Mental State Examination (MMSE) score than the AD group (17.24 \pm 5.43 in the VaD group, $14.88 \pm 6.50$ in the AD group, $\mathrm{p}=0.004$ by Student $\mathrm{t}$ test), indicating that the global cognition of $\mathrm{VaD}$ patients was probably better than that of the $\mathrm{AD}$ patients at a given $\mathrm{CDR}$ index. As expected, the $\mathrm{VaD}$ group had a higher mean modified Hachinski ischemic score than the AD group $(\mathrm{p}<0.001$ by Student $t$ test; table 1).

Table 2 shows the frequencies of MDD and MnDD in the $\mathrm{VaD}$ and $\mathrm{AD}$ groups. MDD was more prevalent in the $\mathrm{VaD}$ group $(20.4 \%$ in the $\mathrm{VaD}$ group, $10.2 \%$ in the $\mathrm{AD}$ group, $\mathrm{p}=0.04, \mathrm{CMH}$ test). The Mantel-Haenszel common $\mathrm{OR}$ for developing MDD in the $\mathrm{VaD}$ group versus the $\mathrm{AD}$ group was estimated to be 2.20 (95\% confidence interval, $\mathrm{CI}=1.02-4.74)$ using the $\mathrm{CMH}$ test $(\mathrm{p}=0.04)$. The OR for developing MDD in the $\mathrm{VaD}$ group versus the $\mathrm{AD}$ group did not differ by the severity of dementia and gender ( $\mathrm{p}=0.1, \mathrm{BD}$ test). Although the OR for developing
MDD were greater in women $(\mathrm{OR}=4.10,95 \% \mathrm{CI}=1.38$ 12.18) than in men $(\mathrm{OR}=1.00,95 \% \mathrm{CI}=0.30-3.33)$, the differences did not reach statistical significance $(\mathrm{p}=0.08$, $\mathrm{BD}$ test). In contrast to $\mathrm{MDD}, \mathrm{MnDD}$ was not more prevalent in the $\mathrm{VaD}$ group (15.7\%) than in the $\mathrm{AD}$ group $(15.7 \%)$ regardless of the dementia severity and gender ( $p>0.1, \mathrm{CMH}$ test). The frequencies of MDD and MnDD tended to fall abruptly in the severe cases $(C D R=3)$ in both $\mathrm{VaD}$ and $\mathrm{AD}$ groups, although the differences did not reach statistical significance ( $p>0.1, \chi^{2}$ test).

Table 3 shows the frequencies of individual depressive symptoms. 'Lost interest in things that used to be pleasurable' was the most prevalent symptom in both $\mathrm{VaD}$ and $\mathrm{AD}$ groups $(37.0 \%$ in the $\mathrm{VaD}$ group, $25.9 \%$ in the $\mathrm{AD}$ group). In the VaD group, 'felt tired and weak all the time' (30.6\%) and 'had to be moving all the time (agitation) and/or felt slowed down' (27.8\%) were the next most prevalent symptoms, whereas in the AD group, 'had to be moving all the time (agitation) and/or felt slowed down' (18.5\%) and 'changed eating habits' (15.7\%) were the next most prevalent symptoms.

All depressive symptoms tended to be more prevalent in the VaD group than in the $\mathrm{AD}$ group. The mean numbers of depressive symptoms were $2.19 \pm 2.64$ in the $\mathrm{VaD}$ group and $1.30 \pm 2.01$ in the $\mathrm{AD}$ group $(\mathrm{p}=0.006$, Student $\mathrm{t}$ test). Of the 9 depressive symptoms, 'changed weight without trying' (16.7\% in the $\mathrm{VaD}$ group, $6.5 \%$ in the $\mathrm{AD}$ group, $\mathrm{p}=0.02, \mathrm{CMH}$ test) and 'felt tired and weak all the time' $(30.6 \%$ in the $\mathrm{VaD}$ group, $13.9 \%$ in the $\mathrm{AD}$ group, $\mathrm{p}=0.003, \mathrm{CMH}$ test) were about 3 times more prevalent in the $\mathrm{VaD}$ group than in the $\mathrm{AD}$ group regardless of demen- 
Fig. 1. The OR and 95\% CI for depressive symptoms in $\mathrm{VaD}$ versus AD. The OR were assessed by Mantel-Haenszel common OR estimates adjusting for the severity of dementia and gender. ${ }^{a} \mathrm{p}=0.01, \mathrm{BD}$ test; ${ }^{\mathrm{b}} \mathrm{p}<0.05,{ }^{\mathrm{c}} \mathrm{p}<0.01, \mathrm{CMH}$ test.

Table 3. Frequencies of depressive symptoms in the $\mathrm{VaD}$ and $\mathrm{AD}$ patients
Felt sad, blue or down in the dumps everyday

Lost interest in things that used to be pleasurable

Changed eating habits

Changed weight without trying

Had difficulty sleeping

Felt tired and weak all the time

Had to be moving all the time (agitation) and/or felt slowed down

Felt worthless, sinful or guilty

Wanted to die or considered suicide

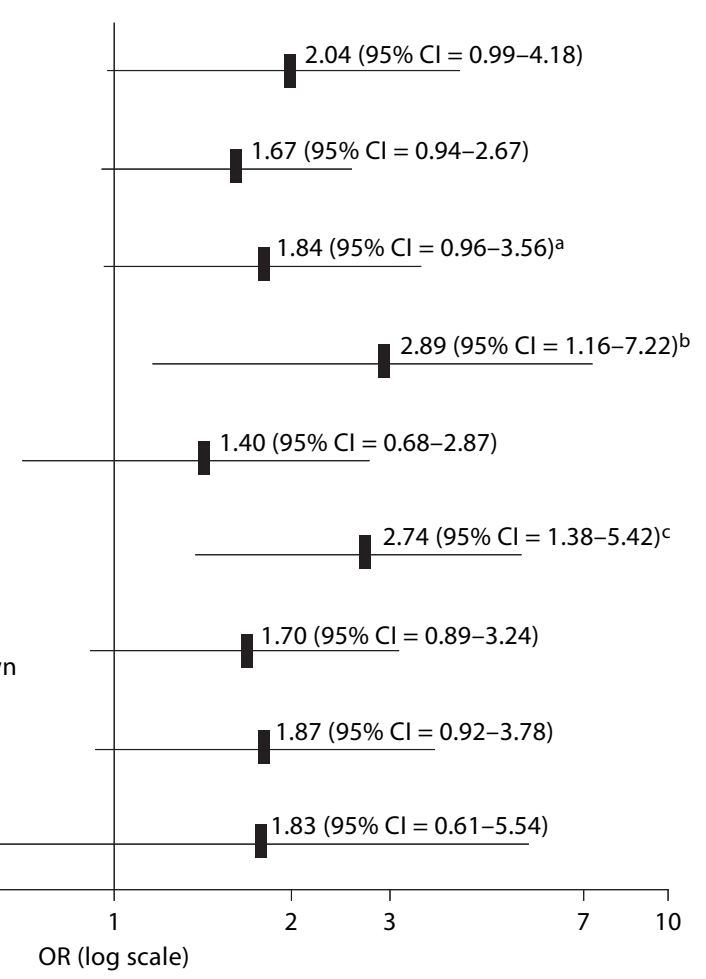

\begin{tabular}{llc}
\hline & VaD $(\mathrm{n}=108)$ & $\mathrm{AD}(\mathrm{n}=108)$ \\
\hline Felt sad, blue or down in the dumps everyday & $25(23.1)$ & $14(13.0)$ \\
Lost interest in things that used to be pleasurable & $40(37.0)$ & $28(25.9)$ \\
Changed eating habits & $28(25.9)$ & $17(15.7)$ \\
Changed weight without trying & $18(16.7)$ & $7(6.5)$ \\
Had difficulty sleeping & $21(19.4)$ & $16(14.8)$ \\
Felt tired and weak all the time & $33(30.6)$ & $15(13.9)$ \\
Had to be moving all the time (agitation) and/or & & \\
$\quad$ felt slowed down & $30(27.8)$ & $20(18.5)$ \\
Felt worthless, sinful or guilty & $25(23.1)$ & $15(13.9)$ \\
Wanted to die or considered suicide & $9(8.3)$ & $5(4.6)$ \\
\hline
\end{tabular}

Figures in parentheses are percentages. tia severity and gender ( $p>0.1, B D$ tests). Differences in the frequencies of 'changed eating habits' were significant only in the female patients with mild disease $(\mathrm{p}=0.01, \mathrm{BD}$ test). The frequencies of 'changed eating habits' were 55.5 and $7.4 \%$ in the female patients with mild $\mathrm{VaD}$ and $\mathrm{AD}$, respectively $(\mathrm{OR}=15.63,95 \% \mathrm{CI}=3.07-79.59)$. The differences in the frequencies of the other 6 symptoms were not statistically significant ( $\mathrm{p}>0.05, \mathrm{CMH}$ test; fig. 1 ).

\section{Discussion}

As has been previously reported $[6,17]$, depressive disorders were quite common in both $\mathrm{VaD}(36.1 \%)$ and $\mathrm{AD}$ patients $(25.9 \%)$ in the present study. In the Canadian Study of Health and Aging, dementia patients were found to be more likely to exhibit depression than those without dementia $(\mathrm{OR}=2.4 ; 95 \% \mathrm{CI}=0.9-3.1)$ [31]. The preva- 
lences of MDD in our $\mathrm{VaD}(20.4 \%)$ and $\mathrm{AD}(10.2 \%)$ groups were higher than the previously reported prevalence of MDD in nondemented Korean elderly subjects (7.5\%) [32] and the weighted average prevalence in community-dwelling older adults (1.8\%) [33]. The prevalence of $\mathrm{MnDD}$ was also higher in the $\mathrm{VaD}(15.7 \%)$ and $\mathrm{AD}$ (15.7\%) groups than its weighted average prevalence in community-dwelling older adults (9.8\%) [33], although the differences were not as large as those of MDD.

In our sample, $\mathrm{VaD}$ patients showed a higher frequency of MDD than the AD patients matched for dementia severity and gender, which is consistent with earlier observations that $\mathrm{VaD}$ patients are more likely to have MDD than $\mathrm{AD}$ patients $[3,4,6,16,34-37]$. However, the OR for developing MDD in $\mathrm{VaD}$ patients versus $\mathrm{AD}$ patients varied widely in the previous studies $(\mathrm{OR}=1.7-8.2)$. Cooper and Mungas [37] estimated the prevalence rate of depression in $810 \mathrm{AD}$ and $502 \mathrm{VaD}$ patients selected from the California Alzheimer's Disease Diagnostic and Treatment Center Program and found an OR of 1.7. In the two studies of Ballard et al. $[4,6]$, the OR were $4.0(95 \% \mathrm{CI}=$ 1.4-11.3) and $2.8(95 \% \mathrm{CI}=1.1-7.0)$. Newman [35] reported that the prevalence rate of MDD was $3.2 \%$ for $\mathrm{AD}$ and $21.3 \%$ for $\mathrm{VaD}$, giving a crude OR of $8.2(95 \% \mathrm{CI}=$ $1.7-40.2)$ in a population sample. In our sample, those were $2.20(95 \% \mathrm{CI}=1.02-4.74)$, which is lower than most of those reported previously $[4,6,34,36]$. Furthermore, the overrepresentation of MDD in $\mathrm{VaD}$ has not been consistently replicated [19-22]. Along with the different diagnostic criteria used, different populations sampled and the different instruments applied, the differences in the severity of dementia and gender within and between the $\mathrm{VaD}$ and $\mathrm{AD}$ groups might have contributed to the wide variability in reported OR $[4,6,34,36,37]$ and conflicting results [19-22], at least in part.

Our study has an advantage over other previous studies in this context because we tightly matched 108 pairs of subjects (one with $\mathrm{VaD}$ and one with $\mathrm{AD}$ ) with respect to gender and CDR. When comparing depression in the different types of dementia, severity of dementia and gender should be matched for the following reasons. First, the prevalence of depression changes with the progression of dementia $[4,17,18]$, and the severity of dementia may vary according to the types of samples (clinical samples, community samples or institutionalized patients) $[38,39]$. Second, nearly twice as many women as men develop depression, and women often have different symptoms. Furthermore, while $\mathrm{VaD}$ is slightly more prevalent among men than women [40], AD is much more prevalent among women $[41,42]$.

Comparison of Depression in $\mathrm{VaD}$ and $\mathrm{AD}$
Although MMSE scores were used to match the severity of dementia in a number of previous studies $[4,16]$, we used the CDR index instead of MMSE scores in matching the global severity of dementia because MMSE with its emphasis on language and memory often inadequately grades the severity of $\mathrm{VaD}$ patients [43]. In our sample, the $\mathrm{VaD}$ group had a higher MMSE score than the $\mathrm{AD}$ group at a given CDR, which indicates that the severity of global cognition may not necessarily coincide with the severity of dementia. If we had used MMSE instead of $\mathrm{CDR}$ to match $\mathrm{VaD}$ and $\mathrm{AD}$ patients, the $\mathrm{VaD}$ group would have probably been deemed to have contained severer cases than the $\mathrm{AD}$ group. This may confound the relation between the type of dementia and depression since the frequencies of these depressive disorders (MDD, $\mathrm{MnDD}$ ) tended to fall abruptly in severe $\mathrm{VaD}$ and $\mathrm{AD}$, as shown by our sample and by previous studies [44, 45]. Difficulty in assessing depression in severe dementia patients may have contributed to a decrease in the prevalence of depression in both $\mathrm{VaD}$ and $\mathrm{AD}$ patients. In terms of pathophysiology, the progression of the central cholinergic deficit may limit the development of major depressive episodes in severe stages in $\mathrm{AD}[8,46]$, whereas this has been little studied in VaD.

Our study also demonstrated that depression is severer in VaD than in $\mathrm{AD}$ when the severities of dementia and gender are similar. Mean numbers of depressive symptoms were significantly higher in the $\mathrm{VaD}$ group, and MDD was more prevalent than MnDD (15.7\%) in the $\mathrm{VaD}$ group but less prevalent in the $\mathrm{AD}$ group. These confirm the earlier observations using unmatched patients [47] or MMSE-matched patients [16].

Compared with the depression in $\mathrm{AD}$, psychomotor symptoms like loss of energy and vegetative symptoms like weight loss and loss of appetite have been reported to be more prevalent in depression co-occurring with $\mathrm{VaD}$ $[16,19,48]$. In our sample, the neurovegetative symptoms ('felt tired and weak all the time', 'changed weight without trying', 'changed eating habits') were more common in $\mathrm{VaD}$ patients than in $\mathrm{AD}$ patients, which further supports earlier observations. Although it is not clear yet why the depression is more retarded and vegetative in $\mathrm{VaD}$ than in $\mathrm{AD}$, different depressogenic mechanisms may account for the different depressive symptom profile between $\mathrm{VaD}$ and $\mathrm{AD}$. Whereas $\mathrm{AD}$ patients show the preferential involvement of more posterior cortical regions that may not play a critical role in the expression of depression, $\mathrm{VaD}$ patients are more likely to exhibit striatopallidothalamocortical pathway damage which may influence motivation and psychomotor speed $[11,12,14]$.

Dement Geriatr Cogn Disord 2007;23:67-73 
In addition, some vegetative symptoms in $\mathrm{VaD}$ patients may stem from comorbid conditions other than depression. For example, weight loss in $\mathrm{VaD}$ patients may stem from the profiles of depressive symptoms or from other medical conditions such as immobilization and difficulties with food intake.
In conclusion, regardless of the severity of dementia and gender, depression was found to be more frequent, severer, more retarded and vegetative in $\mathrm{VaD}$ than in $\mathrm{AD}$.

\section{References}

1 Baldwin RC, Benbow SM, Marriott A, Tomenson B: Depression in old age: a reconsideration of cerebral disease in relation to outcome. Br J Psychiatry 1993;163:82-90.

2 Drinka TJ, Smith JC, Drinka PJ: Correlates of depression and burden for informal caregivers of patients in a geriatrics referral clinic. J Am Geriatr Soc 1987;35:522-525.

-3 Ballard C, Bannister C, Oyebode F: A review - Depression in dementia sufferers. Int J Geriatr Psychiatry 1996;11:507-515.

-4 Ballard C, Neill D, O’Brien J, McKeith IG, Ince P, Perry R: Anxiety, depression and psychosis in vascular dementia: prevalence and associations. J Affect Disord 2000;59:97106.

-5 Burns A: Affective symptoms in Alzheimer's disease. Int J Geriatr Psychiatry 1991;6:371376.

-6 Ballard C, Bannister C, Solis M, Oyebode F, Wilcock G: The prevalence, associations and symptoms of depression amongst dementia sufferers. J Affect Disord 1996;36:135-144.

7 Migliorelli R, Teson A, Sabe L, Petracchi M, Leiguarda R, Starkstein SE: Prevalence and correlates of dysthymia and major depression among patients with Alzheimer's disease. Am J Psychiatry 1995;152:37-44.

-8 Zubenko GS, Moossy J, Kopp U: Neurochemical correlates of major depression in primary dementia. Arch Neurol 1990;47: 209-214.

-9 Zweig RM, Ross CA, Hedreen JC, Steele C, Cardillo JE, Whitehouse PJ, Folstein MF, Price DL: The neuropathology of aminergic nuclei in Alzheimer's disease. Ann Neurol 1988;24:233-242.

10 Forstl H, Burns A, Luthert P, Cairns N, Lantos P, Levy R: Clinical and neuropathological correlates of depression in Alzheimer's disease. Psychol Med 1992;22:877-884.

11 Brun A: Pathology and pathophysiology of cerebrovascular dementia: pure subgroups of obstructive and hypoperfusive etiology. Dementia 1994;5:145-147.

-12 Rockwood K, Bowler J, Erkinjuntti T, Hachinski V, Wallin A: Subtypes of vascular dementia. Alzheimer Dis Assoc Disord 1999; 13(suppl 3):S59-S65.

13 Provinciali L, Coccia M: Post-stroke and vascular depression: a critical review. Neurol Sci 2002;22:417-428.
14 Krishnan KR, Hays JC, Blazer DG: MRI-defined vascular depression. Am J Psychiatry 1997;154:497-501.

-15 Simpson S, Allen H, Tomenson B, Burns A: Neurological correlates of depressive symptoms in Alzheimer's disease and vascular dementia. J Affect Disord 1999;53:129-136.

-16 Sultzer DL, Levin HS, Mahler ME, High WM, Cummings JL: A comparison of psychiatric symptoms in vascular dementia and Alzheimer's disease. Am J Psychiatry 1993; 150:1806-1812.

17 Starkstein SE, Jorge R, Mizrahi R, Robinson RG: The construct of minor and major depression in Alzheimer's disease. Am J Psychiatry 2005;162:2086-2093.

18 Zubenko GS, Zubenko WN, McPherson S, Spoor E, Marin DB, Farlow MR, Smith GE, Geda YE, Cummings JL, Petersen RC, Sunderland T: A collaborative study of the emergence and clinical features of the major depressive syndrome of Alzheimer's disease. Am J Psychiatry 2003;160:857-866.

19 Ballard CG, Cassidy G, Bannister C, Mohan RN: Prevalence, symptom profile, and aetiology of depression in dementia sufferers. J Affect Disord 1993;29:1-6.

20 Bucht G, Adolfsson R, Winblad B: Dementia of the Alzheimer type and multi-infarct dementia: a clinical description and diagnostic problems. J Am Geriatr Soc 1984;32:491498.

21 Reding M, Haycox J, Blass J: Depression in patients referred to a dementia clinic. A three-year prospective study. Arch Neurol 1985;42:894-896.

22 Fischer P, Simanyi M, Danielczyk W: Depression in dementia of the Alzheimer type and in multi-infarct dementia. Am J Psychiatry 1990;147:1484-1487.

23 Immerman RS, Mackey WC: The depression gender gap: a view through a biocultural filter. Genet Soc Gen Psychol Monogr 2003; 129:5-39.

24 Kendler KS: Gender differences in the genetic epidemiology of major depression. J Gend Specif Med 1998;1:28-31.

25 Kuehner C: Gender differences in unipolar depression: an update of epidemiological findings and possible explanations. Acta Psychiatr Scand 2003;108:163-174.
26 Lee JH, Lee KU, Lee DY, Kim KW, Jhoo JH, Kim JH, Lee KH, Kim SY, Han SH, Woo JI: Development of the Korean version of the Consortium to Establish a Registry for Alzheimer's Disease Assessment Packet (CERAD-K): clinical and neuropsychological assessment batteries. J Gerontol B Psychol Sci Soc Sci 2002;57:P47-P53.

27 Rosen WG, Terry RD, Fuld PA, Katzman R, Peck A: Pathological verification of ischemic score in differentiation of dementias. Ann Neurol 1980;7:486-488.

28 American Psychiatric Association: Diagnostic and Statistical Manual of Mental Disorders, ed 4 (DSM-IV). Washington, American Psychiatric Association, 1994.

29 Roman GC, Tatemichi TK, Erkinjuntti T, Cummings JL, Masdeu JC, Garcia JH, Amaducci L, Orgogozo JM, Brun A, Hofman A, et al: Vascular dementia: diagnostic criteria for research studies. Report of the NINDSAIREN International Workshop. Neurology 1993;43:250-260.

30 McKhann G, Drachman D, Folstein M, Katzman R, Price D, Stadlan EM: Clinical diagnosis of Alzheimer's disease: report of the NINCDS-ADRDA Work Group under the auspices of Department of Health and Human Services Task Force on Alzheimer's Disease. Neurology 1984;34:939-944.

- 31 Ostbye T, Kristjansson B, Hill G, Newman SC, Brouwer RN, McDowell I: Prevalence and predictors of depression in elderly Canadians: the Canadian Study of Health and Aging. Chronic Dis Can 2005;26:93-99.

32 Suh GH, Kim JK, Yeon BK, Park SK, Yoo KY, Yang BK, Kim YI, Cho MJ: Prevalence and risk factors of dementia and depression in the elderly. J Korean Neuropsychiatr Assoc 2000;39:809-824.

33 Beekman AT, Copeland JR, Prince MJ: Review of community prevalence of depression in later life. Br J Psychiatry 1999; 174:307311.

34 Greenwald BS, Kramer-Ginsberg E, Marin DB, Laitman LB, Hermann CK, Mohs RC, Davis KL: Dementia with coexistent major depression. Am J Psychiatry 1989;146:14721478.

35 Newman SC: The prevalence of depression in Alzheimer's disease and vascular dementia in a population sample. J Affect Disord 1999;52:169-176. 
36 Reichman WE, Coyne AC: Depressive symptoms in Alzheimer's disease and multi-infarct dementia. J Geriatr Psychiatry Neurol 1995;8:96-99.

-37 Cooper JK, Mungas D: Risk factor and behavioral differences between vascular and Alzheimer's dementias: the pathway to endstage disease. J Geriatr Psychiatry Neurol 1993;6:29-33.

38 Mayeux R: Diagnostic problems in nursing home patients with dementia: why we should and how we can improve accuracy. Alzheimer Dis Assoc Disord 1994;8(suppl 1):S184-S187.

-39 Boller F, Verny M, Hugonot-Diener L, Saxton J: Clinical features and assessment of severe dementia: a review. Eur J Neurol 2002; 9:125-136.

40 Rocca WA, Kokmen E: Frequency and distribution of vascular dementia. Alzheimer Dis Assoc Disord 1999;13(suppl 3):S9-S14.
41 Andersen K, Launer LJ, Dewey ME, Letenneur L, Ott A, Copeland JR, Dartigues JF, Kragh-Sorensen P, Baldereschi M, Brayne C, Lobo A, Martinez-Lage JM, Stijnen T, Hofman A: Gender differences in the incidence of $\mathrm{AD}$ and vascular dementia: the EURODEM studies. EURODEM Incidence Research Group. Neurology 1999;53:1992-1997.

42 Fratiglioni L, Viitanen M, von Strauss E, Tontodonati V, Herlitz A, Winblad B: Very old women at highest risk of dementia and Alzheimer's disease: incidence data from the Kungsholmen Project, Stockholm. Neurology 1997;48:132-138.

43 van Gorp WG, Marcotte TD, Sultzer D, Hinkin C, Mahler M, Cummings JL: Screening for dementia: comparison of three commonly used instruments. J Clin Exp Neuropsychol 1999;21:29-38.

44 Forsell Y, Jorm AF, Fratiglioni L, Grut M, Winblad B: Application of DSM-III-R criteria for major depressive episode to elderly subjects with and without dementia. Am J Psychiatry 1993;150:1199-1202.
45 Lopez OL, Becker JT, Sweet RA, Klunk W, Kaufer DI, Saxton J, Habeych M, De Kosky ST: Psychiatric symptoms vary with the severity of dementia in probable Alzheimer's disease. J Neuropsychiatry Clin Neurosci 2003;15:346-353.

46 Zubenko GS, Rosen J, Sweet RA, Mulsant $\mathrm{BH}$, Rifai AH: Impact of psychiatric hospitalization on behavioral complications of Alzheimer's disease. Am J Psychiatry 1992; 149:1484-1491.

47 Cummings JL, Miller B, Hill MA, Neshkes R: Neuropsychiatric aspects of multi-infarct dementia and dementia of the Alzheimer type. Arch Neurol 1987;44:389-393.

48 Naarding P, de Koning I, van Kooten F, Dippel DW, Janzing JG, van der Mast RC, Koudstaal PJ: Depression in vascular dementia. Int J Geriatr Psychiatry 2003;18:325-330. 